
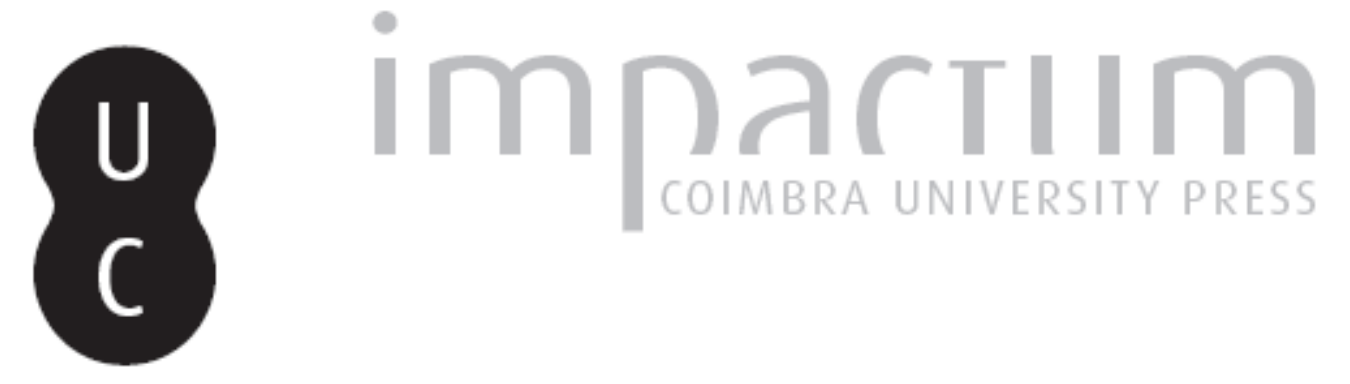

\title{
'Stare decisis' e súmula vinculante: uma análise comparativa sobre a vinculação das decisões na jurisdição constitucional
}

Autor(es): $\quad$ Carvalho, Alexandre Douglas Zaidan de

Publicado por: Universidade Católica de Petrópolis

URL persistente:

URI:http://hdl.handle.net/10316.2/33769

DOI:

DOI:http://dx.doi.org/10.14195/2175-0947_4-2_1

Accessed : $\quad$ 26-Apr-2023 11:00:48

A navegação consulta e descarregamento dos títulos inseridos nas Bibliotecas Digitais UC Digitalis, UC Pombalina e UC Impactum, pressupõem a aceitação plena e sem reservas dos Termos e Condições de Uso destas Bibliotecas Digitais, disponíveis em https://digitalis.uc.pt/pt-pt/termos.

Conforme exposto nos referidos Termos e Condições de Uso, o descarregamento de títulos de acesso restrito requer uma licença válida de autorização devendo o utilizador aceder ao(s) documento(s) a partir de um endereço de IP da instituição detentora da supramencionada licença.

Ao utilizador é apenas permitido o descarregamento para uso pessoal, pelo que o emprego do(s) título(s) descarregado(s) para outro fim, designadamente comercial, carece de autorização do respetivo autor ou editor da obra.

Na medida em que todas as obras da UC Digitalis se encontram protegidas pelo Código do Direito de Autor e Direitos Conexos e demais legislação aplicável, toda a cópia, parcial ou total, deste documento, nos casos em que é legalmente admitida, deverá conter ou fazer-se acompanhar por este aviso.

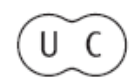



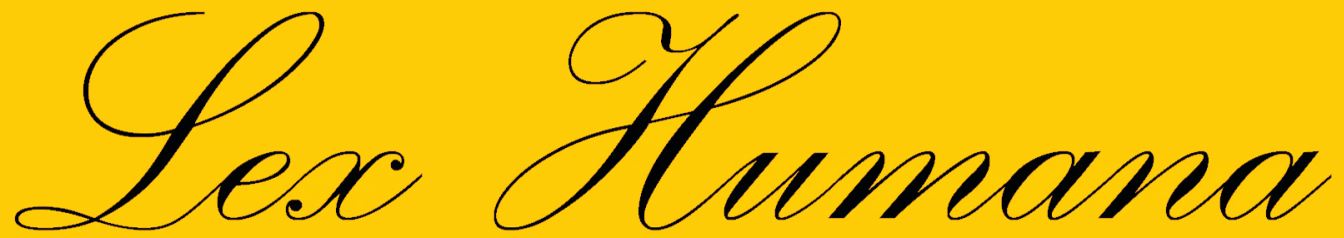

Revista do Programa de Pós-Graduação em Direito da UCP

ISSN(e) 2175-0947

Universidade Católica de Petrópolis Rua Benjamin Constant, 213 - Petrópolis - Centro CEP 25610-130

Tel: (24) 2244-4000 E-mail: lexhumana@ucp.br 


\section{'STARE DECISIS' E SÚMULA VINCULANTE: UMA ANÁLISE COMPARATIVA SOBRE A VINCULAÇÃO DAS DECISÕES NA JURISDIÇÃO CONSTITUCIONAL ${ }^{1}$}

Alexandre Douglas Zaidan de Carvalho

Resumo: O objeto do artigo consiste na investigação do conceito de stare decisis na jurisdição norte-americana e como ele desempenha uma função limitadora da discrição judicial, estabelecendo, a um só tempo, a estabilidade da interpretação constitucional e certa flexibilidade jurisprudencial, capaz de evitar a cristalização de decisões em descompasso com as mudanças desencadeadas na sociedade. Em seguida, será analisado o instituto das súmulas vinculantes no direito brasileiro, procurando compreender qual significado ele assume no sistema judicial brasileiro, tanto como instrumento de concentração da jurisdição constitucional ou quanto expressão do exercício de uma normatividade positiva pelo Supremo Tribunal Federal.

Palavras-chave: Stare decisis; Súmula vinculante; Jurisdição constitucional.

Abstract: The object of this paper is to investigate the concept of stare decisis in U.S. jurisdiction and how it plays a role in limiting judicial discretion, establishing at the same time, the stability of constitutional interpretation and judicial flexibility, able to avoid crystallization decisions in step with changes in society triggered. Then, the institute will analyze the binding precedents in Brazilian law, trying to understand what meaning he takes on Brazilian judicial system, both as a means of pooling the constitutional jurisdiction of the exercise or expression as a positive normativity by the Supreme Court.

Keywords: Stare decisis; binding docket; constitutional adjudication.

\footnotetext{
1 Artigo recebido em 17/03/2012 e aprovado para publicação pelo Conselho Editorial em 20/07/2012.

2 Doutorando em Direito pela Universidade de Brasília. Mestre em Direito pela UFPE. Currículo Lattes: http://lattes.cnpq.br/9329102524031487. E-mail: douglas.zaidan@gmail.com.
} 


\section{Introdução: a ideia de vinculação das decisões na jurisdição constitucional.}

A permanência do intercâmbio entre o ideal normativo encartado em um texto constitucional e a realidade experimentada pelas instituições parece confirmar a assertiva de que as democracias constitucionais caracterizam-se pelo "impulso de um dever ser e pela resistência de um é" , cujo produto resulta numa sequência de tentativas, erros e acertos.

Do mesmo modo como Giovanni Sartori procura estabelecer uma relação entre as definições descritiva e prescritiva de democracia, que se influenciam mutuamente e assim constituem o seu próprio conceito, as intersecções entre a jurisdição constitucional e os diversos fatores político-institucionais no regime democrático parecem seguir uma lógica semelhante.

Talvez não seja por outro motivo que, em diversos momentos da experiência democrática regidos por uma Constituição, a prevalência do entendimento firmado sobre aquele "dever ser" exige a sua observância pelos agentes envolvidos no processo de construção do sentido da política, sejam os poderes constituídos, os grupos sociais representantes da maioria e das minorias ou os diversos cidadãos, individualmente considerados.

Essa tem sido uma das marcas inconfundíveis da jurisdição constitucional nas democracias contemporâneas, fixar a interpretação do "dever ser" consignado no texto da Constituição, mesmo contra a "resistência de um é", impondo o resultado daquela sobre esta.

$\mathrm{Na}$ força impositiva dos julgados proferidos pela jurisdição constitucional reside, segundo Kelsen ${ }^{4}$, a justificativa para a ideia de efeito vinculante das decisões do órgão encarregado de exercê-la, de modo a impedir a ocorrência de decisões conflitantes entre os diversos órgãos judiciais e administrativos do Estado.

De acordo com o raciocínio kelseniano, não faria sentido destinar a função jurisdicional a um órgão do Estado, em decorrência da supralegalidade da Constituição, das liberdades políticas e dos direitos fundamentais, caso não se atribuísse a essa função a capacidade de tornar obrigatórios os comportamentos dos indivíduos e do próprio Estado com base no resultado da interpretação das normas constitucionais.

A vinculação das decisões da jurisdição constitucional seria, então, a aptidão de abranger uma dada relação jurídica entre determinados sujeitos, ou entre estes e o Estado,

\footnotetext{
${ }^{3}$ SARTORI, Giovanni. A teoria da democracia revisitada: o debate contemporâneo, Vol. I. tradução: Dinah de Abreu Azevedo. São Paulo: Ática, 1994. p. 24.

${ }^{4}$ KELSEN, Hans. Jurisdição constitucional. São Paulo: Martins Fontes, 2003, p. 306.
} 
sob a eficácia da compreensão delineada pelo principal órgão responsável pela interpretação da Constituição.

Seguindo a lógica de instituir uma série de direitos numa Constituição escrita como forma de reger a ação política estatal, as razões para a adoção do efeito vinculante na jurisdição são de ordem normativa, e dizem respeito ao alcance e às consequências da interpretação constitucional num dado contexto fático apresentado, fundada na pretensão de se conferir observância a um comando abstrato extraído do texto constitucional.

A percepção dessa natureza peculiar da atividade destinada à jurisdição constitucional contemporânea, que reforça o conteúdo da interpretação da Constituição para dar-lhe contorno normativo mais efetivo, acaba se convertendo no discurso de sustentação da jurisprudência vinculante como necessidade do Estado de Direito, que enfrenta como problema, por sua vez, a tentativa de articular os conceitos de independência judicial e segurança jurídica.

Tomando por objeto do precedente a sua ratio decidendi ou o elemento essencial extraído da decisão no contexto específico do caso julgado, surge a questão sobre em que consiste a sua força, não o poder persuasivo das razões de fato e de direito delineadas na decisão, mas o caráter obrigatório e inevitavelmente vinculante que submete os juízes ao dever de segui-lo.

Juan Igartua Salaverría ${ }^{5}$ procura sistematizar os desacordos em torno da obrigatoriedade da força vinculante de um julgado segundo a lógica do "ser" e do "dever ser", dividindo originalmente o precedente em duas correntes: a primeira no sentido de que o precedente é vinculante e ainda que não seja deveria sê-lo; opondo-se à essa idéia, a segunda corrente consistiria em afirmar que o precedente não é vinculante e nem deveria ser.

Em seguida, Salaverría combina as categorias criadas para estabelecer quatro possibilidades acerca da adoção ou não dos precedentes vinculantes na jurisdição constitucional, são elas: 1) o precedente é vinculante e deve sê-lo; 2) o precedente é vinculante, mas não deveria sê-lo; 3) o precedente não é vinculante, mas deveria sê-lo; e 4) o precedente não é vinculante nem deve sê-lo.

A formulação descrita acima abre uma série de opções, cuja escolha coerente exige o exame da configuração do instituto do efeito vinculante (inclusive das súmulas) no texto da

5 SALAVERRIA, Juan Igartua. La fuerza vinculante del precedente judicial. Isegoría, $\mathrm{n}^{\circ} 35$, julio-diciembre, 2006, p. 194. 
Constituição e a adequação entre essa estrutura normativa e o efetivo cumprimento do papel da jurisdição constitucional no Estado Democrático de Direito.

Por tal motivo, ganha importância a discussão sobre o âmbito de generalidade (objetiva e subjetiva) que o efeito vinculante das decisões apresenta, levantando a necessidade de definição sobre o que efetivamente deve tornar-se obrigatório a partir de uma interpretação da Constituição e quem deve ser atingido pela força normativa da decisão.

O presente artigo tem como objeto a comparação entre os institutos da doctrine of stare decisis e a súmula vinculante, pertencentes às distintas tradições jurídicas, norte-americana e brasileira, pontuando suas semelhanças e distinções quanto às possibilidades de vinculação das decisões em matéria constitucional em ambos os sistemas.

\section{O stare decisis e a força do precedente na jurisdição norte-americana.}

Tal qual o entendimento de que aos juízes cabia a observância de eventual incompatibilidade entre a norma derivada da atividade do Parlamento e a Constituição, a regra que confere força vinculante aos precedentes judiciais nos Estados Unidos também não decorre de qualquer previsão do texto constitucional de 1787, tendo sido, igualmente, criação pretoriana reiterada pela prática institucional daquele país.

O sistema jurídico norte-americano, herdeiro da tradição jurídica do common law inglês, tem com este vários institutos jurídicos em comum, entre eles o respeito ao precedente judicial como elemento fundamental da organização judiciária, cujo fundamento reside na necessidade de conferir estabilidade e uniformidade à aplicação do direito, orientadores da regra do stare decisis ${ }^{6}$.

Sem adentrar em comparações históricas sobre o desenvolvimento do direito na Inglaterra e nos Estados Unidos, registra-se que grande parte da importância do conceito de stare decisis tanto para o direito inglês quanto para o norte-americano está na limitação do arbítrio das cortes judiciais ${ }^{7}$, especialmente na característica de adotar como ponto de partida nos seus julgamentos, um determinado caso ou casos cuja influência para a solução

\footnotetext{
${ }^{6} \mathrm{O}$ stare decisis consiste no precedente judicial vinculante formulado a partir do exame de um caso concreto pelo Poder Judiciário nos Estados Unidos e que limita o arbítrio dos demais órgãos judiciais quando do julgamento posterior de questão semelhante, contribuindo para o aumento de previsibilidade das decisões no sistema judiciário norte-americano. Para Sérgio Resende de Barros "É o stare decisis uma condição jurisprudencial natural ao common law."

${ }_{7}$ Para Neil Duxbury a rejeição da regra do precedente juiz no common law equivaleria ao descumprimento de uma obrigação moral, admitindo-se apenas quando apresentadas justificativas suficientes. Cf. DUXBURY, Neil. The nature and authority of precedent. New York: Cambridge University Press, 2008, p. 113.
} 
do litígio apreciado pode ser maior ou menor, a depender da força vinculante ou apenas persuasiva do(s) precedente(s) examinado(s).

E embora seja correta a afirmação de que nem todos os precedentes têm caráter vinculante (binding effects), sendo necessário perquirir em cada julgado a força do caso paradigma, é fato que a doctrine of stare decisis confere certa estabilidade e previsibilidade ao comportamento do Poder Judiciário, evitando mudanças bruscas de entendimento sobre questões de direito, o que contribui para que as decisões consolidadas não sejam facilmente alteradas, segundo a composição dos tribunais ou das preferências políticas de seus membros.

A sustentação do instituto do precedente encontra vários argumentos, que podem ser agrupados segundo fundamentos ligados à hierarquia judicial; segurança jurídica; isonomia; uniformidade do direito; imparcialidade da decisão; confiança no sistema judiciário e previsibilidade da justiça, que revelam, ainda de forma implícita, uma consequência de ordem prática, qual seja a de "demover os litigantes de retornar ao Judiciário na ilusão de obter uma resposta diferente para o seu caso".

Adquirindo o direito estadunidense feição diferenciada do common law britânico", muito em função de algumas de suas características próprias como a existência de uma Constituição escrita, o princípio da supremacia da constituição, o fato de ser uma federação, a forte descentralização do poder judicial, a existência de códigos, para citar apenas as mais importantes, lembradas por Marcelo Alves Dias de Souza ${ }^{10}$, também a

\footnotetext{
8 PORTO, Sérgio Gilberto. Sobre a common law, civil law e o precedente judicial. Estudo em homenagem ao Professor Egas Moniz de Aragão. Academia Brasileira de Direito Processual Civil. Disponível em: http://www.abdpc.org.br/abdpc/artigos/Sergio\%20Porto-formatado.pdf. Acesso em: 13 jul. 2010.

${ }^{9} \mathrm{Em}$ análise sobre a evolução do constitucionalismo britânico, Bruno Galindo aponta algumas características do common law, alertando para o equívoco da referência comum ao direito inglês como não escrito e costumeiro, na seguinte passagem: "O common law, muitas vezes referido como direito não escrito e como direito costumeiro, não é nem uma coisa nem outra. Ele é escrito, na medida em que surge das decisões judiciais, sobretudo dos Tribunais de Westminster, que consolidam, a partir do século XIII, um direito comum a toda a Inglaterra, em oposição aos costumes locais. Também não é costumeiro, visto que surge da jurisprudência e vem justamente tomar o lugar de determinados costumes. Consiste fundamentalmente nos precedentes judiciais que possuem força obrigatória. No caso do direito constitucional, somente os precedentes referentes às matérias constitucionais é que passam a fazer parte do direito da Constituição." In: GALINDO, Bruno. A teoria da constituição no common law. Reflexões teóricas sobre o peculiar constitucionalismo britânico. Revista de informação legislativa. Senado Federal, Brasília a. 41, n. 164, p. 303-316, out./dez. 2004, p. 309.

10 “As diferenças existentes são, mais uma vez, plenamente justificáveis. Primeiramente, o número de precedentes nos Estados Unidos, acerca de qualquer matéria, é bem maior. Um desenvolvido sistema de Justiça Federal, ao lado de dezenas de sistemas estaduais, faz com que se tenham comumente precedentes contraditórios. E isso dá aos juízes, muitas vezes, a possibilidade de escolha do precedente mais adequado. Em segundo lugar, a rápida expansão econômica americana implica constantes mudanças políticas e sociais e isso sugere, comparando-se com a gradual evolução da Inglaterra, que a estrita adoção da doutrina do stare decisis seja mais difícil e problemática. Por derradeiro, as questões constitucionais têm um papel bem mais preponderante nos Estados Unidos. Como se sabe, a interpretação do Direito Constitucional - Direito eminentemente político - deve ser caracterizada pela flexibilidade. E essa flexibilidade, quando da aplicação
} 
doutrina norte-americana do stare decisis passa a ser informada por uma maior fluidez do que no direito inglês, como ressalta aquele autor:

A flexibilidade com que o stare decisis foi adotado entre os norte-americanos é observada em diversos julgados da Suprema Corte, como o destacado Hertz. v. Woodman (218 U.S. 215) de 1910, dentre outros lembrados por Eduardo Sodero, quando apoiou a afirmação de que o stare decisis não é um "comando inexorável"11.

O reconhecimento dessa flexibilidade do precedente, que em princípio não se constitui em um "comando inexoráxel” cristalizado está relacionado à própria forma de surgimento do stare decisis nas raízes pragmáticas do common law, com sua relativa desvinculação de modelos abstratos representados pela lei em tese, alçada à fonte primária do direito, para privilegiar a experiência judicial ao ponto de elevar os efeitos de um julgado à condição de precedente vinculante a casos futuros de semelhante situação fático-jurídica.

Foi a partir dessa concepção prática dos operadores jurídicos no direito norteamericano que o método lógico-indutivo de raciocínio a partir de casos foi desenvolvido, dando origem a alguns mecanismos de revogação ou superação dos precedentes sem necessariamente implicar na afirmação de que a decisão-paradigma de um determinado Tribunal estava equivocada ${ }^{12}$ e precisa ser corrigida, noção importante para a manutenção da coerência do próprio sistema.

Entre esses mecanismos está o distinguishing ${ }^{13}$, que consiste na recusa de aplicação do precedente pelo juiz no caso examinado em função de suas particularidades fáticas, materialmente distintas das condições do precedente, justificando a negativa de eficácia do caso predecessor na hipótese concreta examinada.

Aqui o operador do direito depara-se com o dever de observação detida sobre os fatos materialmente relevantes do caso paradigma, além de considerar alguns fatores ${ }^{14}$ como o eventual conflito normativo com a regra de outros precedentes aplicáveis, em tese; existência de equívoco quanto à apreciação do caso predecessor pela corte em que se

dos precedentes judiciais constitucionais, necessariamente contamina as outras áreas do Direito." In: SOUZA, Marcelo Alves Dias de. Do precedente judicial à súmula vinculante, p. 92.

${ }^{11}$ SODERO, Eduardo. Sobre el cambio de los precedentes. Revista Isonomía, Instituto Tecnológico Autónomo de Mexico, no 21, Octubre/2004.

${ }^{12}$ DUXBURY, Neil. The nature and authority of precedent. New York: Cambridge University Press, 2008, p. 118.

13 Para Duxbury o instituto mostra a variedade da força dos precedentes a depender da área do direito discutida, conforme descreve na seguinte passagem: "As consequências da distinção podem variar de acordo com o campo do direito: em algumas áreas do direito, por exemplo, um conjunto de precedentes permancem em grande parte intactos ou bem estabelecidos como marco da decisão (...) podem induðir um grau especialmente elevado de confiança por parte dos litigantes em potencial, e assim as distinções nessas áreas podem causar mais descontentamento do que seria em áreas onde a decisão de litigar é menos influenciada pela previsibilidade dos resultados". Tradução livre. In: DUXBURY, Neil. The nature and authority of precedent. New York: Cambridge University Press, 2008, p. 113/114.

${ }^{14}$ DUXBURY, Neil. The nature and authority of precedent. New York: Cambridge University Press, 2008, p. 115. 
originou o precedente; os limites delineados pela corte responsável pelo precedente, e se esses limites autorizam a sua aplicação ao caso apreciado.

A técnica do distinguishing consiste em eliminar as eventuais incongruências na apreciação comparativa de casos no common law, representando uma maneira menos traumática de revogação da eficácia obrigatória resultante de um julgado a que está submetido o juiz, sem comprometer a coesão do sistema, trata-se de uma revogação parcial, pois, o precedente permanecerá válido para outras hipóteses.

Outra técnica de superação do precedente é a sua revogação total, conhecida entre os norte-americanos como overruling. Mesmo havendo contexto fático idêntico ${ }^{15}$, a Corte ou o juiz do caso oferece razão jurídica distinta para sua solução, justificando a não aplicação da regra do precedente, situação que importa na revogação deste.

Embora ambos os institutos concedam, de forma limitada, certos poderes legislativos ao operador do Direito ${ }^{16}$, a prática do distinguishing revela a inadequação do precedente apenas para o caso examinado, configurando-se em revogação parcial, já o overruling constitui-se de revogação radical da força obrigatória do caso paradigma, e geralmente só pode ser feito por uma Corte hierarquicamente superior àquela responsável pela decisão a ser revogada.

A revogação perpetrada pelo overruling pode ser expressa ou implícita, ocorrendo desta forma quando das razões expostas na decisão fique claro que a regra de direito contida no precedente não tem mais eficácia, mesmo que não conste dos termos da decisão. A revogação, mesmo sendo total, pode atingir apenas parte da regra de direito firmada no precedente (envolve toda a lógica de parte de uma decisão, como o julgamento de uma preliminar processual no direito brasileiro), sem prejuízo da sua posterior aplicação a outros casos.

Entre os motivos da revogação, pode-se encontrar a ocorrência de uma mudança social subsequente ${ }^{17}$ à elaboração da regra a ser revogada, que provoca o reconhecimento da inadequação do precedente à complexidade do caso ou mesmo a constatação da imperfeição da norma contida no precedente desde a sua formação.

\footnotetext{
${ }^{15}$ Idem, p. 117.

${ }^{16}$ Idem, p. 116/117.

17 Para Raimo Siltala o overruling "significa uma invalidação formal de um precedente, quando não há razões suficientes para a distinção entre os dois casos. O juiz subsequente também pode simplesmente preferir ignorar expressamente a decisão anterior, uma vez que foi ultrapassada pela força de alterações posteriores na sociedade, ou porque a regra é considerada como 'imperfeita' desde o início." Tradução livre. In: SILTALA, Raimo. A theory of precedent: from analytical positivism to a post-analytical philosophy of law. Portland: Hart Publishing, 2000, p. 73.
} 
Esses e outros institutos evidenciam o relativismo conferido pelos temperamentos da doutrina norte-americana do stare decisis, que possibilitaram a manutenção de um direito eminentemente jurisprudencial, baseado em análises de distinções fáticas entre o caso paradigma e o que se põe ao exame do julgador, sem o prejuízo da existência de regras escritas.

\section{A súmula vinculante com instrumento da concentração da jurisdição constitucional brasileira.}

Passo significativo na tentativa da EC n ${ }^{\circ}$ 45/2004 de privilegiar a interpretação constitucional do Supremo Tribunal Federal sobre os demais órgãos judiciais e da administração pública foi a introdução da súmula vinculante, que embora não fosse uma idéia original no direito brasileiro ${ }^{18}$, ressurgiu como uma alternativa capaz de dar tratamento uniforme à questões pacificadas pela Corte.

Tal qual ocorreu com a repercussão geral, a regulamentação da edição, revisão e cancelamento das súmulas vinculantes só veio a ser estabelecida dois anos após a reforma constitucional, com a publicação da Lei n ${ }^{\circ} 11.417$, de 19 de dezembro de 2006, que repetiu em seu texto os requisitos do art. 103-A e parágrafos, da Constituição, acrescentando-lhe poucas inovações ${ }^{19}$.

\footnotetext{
${ }^{18}$ Embora não se possa afirmar que sejam idênticos, a finalidade e a estrutura normativa da súmula vinculante guarda alguns pontos em comum com os antigos assentos portugueses, que tiveram aplicação no Brasil imperial, por força do Decreto n 2.684, de 23 de outubro de 1875 (sobre a aplicação dos assentos da Casa de Suplicação de Lisboa e conferia competência ao Supremo Tribunal de Justiça para editar outros) e Decreto $\mathrm{n}^{\circ}$ 6.142, de 10 de março de 1876 (regulando a forma de edição dos assentos do Supremo Tribunal de Justiça). O instituto dos assentos vigorou em Portugal até dezembro de 1993, quando o Tribunal Constitucional declarou inconstitucional norma do art. $2^{\circ}$ do Código Civil português que atribuía ao Supremo Tribunal de Justiça (órgão superior da hierarquia dos tribunais judiciais, sem prejuízo da competência própria do Tribunal Constitucional) a competência para editar os "assentos" de "doutrina com força obrigatória geral", por tal prática não ser reconhecida como fonte do direito, de acordo com a Constituição portuguesa de 1976. Tribunal Constitucional de Portugal. Acórdão $\mathrm{n}^{\circ}$ 810/1993. Inteiro teor do julgado disponível em: http://www.tribunalconstitucional.pt/tc/acordaos/19930810.html Acesso em: 06.04.2011. Sobre a aplicação dos antigos assentos portugueses no Brasil: CUNHA, Sérgio Sérvulo da. A arcaica súmula vinculante. Revista latino-americana de estudos constitucionais, $\mathrm{n}^{\circ}$ 5, p. 475-499, jan./jun. 2005, p. 483. Também: DANTAS, Ivo. Constituição e processo. $2^{2}$ edição. Curitiba: Juruá, 2007, p. 526-529. Uma análise sobre os limites da comparação entre o instituto dos assentos portugueses e a súmula vinculante é encontrada em LEITE, Glauco Salomão. Súmula vinculante e jurisdição constitucional brasileira. Rio de Janeiro: Forense, 2007, p. 122-128.

${ }^{19}$ Entre as novidades apresentadas estão a inclusão do Defensor Público-Geral da União e dos Tribunais entre os legitimados para propor a edição, a revisão e o cancelamento de súmula vinculante (art. $3^{\circ}$, VI e XI); no mesmo sentido, a possibilidade de proposição dos Municípios, desde que incidentalmente no curso de processo em que seja parte $\left(\right.$ art. $3^{\circ}, \$ 1^{\circ}$ ); a previsão da manifestação de terceiros no procedimento (art. $3^{\circ}$, $\left.\$ 2^{\circ}\right)$; a fixação de sua eficácia imediata, salvo manifestação de $2 / 3$ dos Ministros, tal qual previsto no art. 27 da Lei 9.868/99 (art. $4^{\circ}$ ); o dever de revisão ou cancelamento da súmula no caso alteração ou revogação da lei em que se fundou a interpretação do Tribunal para a edição do enunciado. In: BRASIL. Lei n 11.417, de 19 de dezembro de 2006. Disponível em: http://www.planalto.gov.br/ccivil_03/Ato20042006/2006/Lei/L11417.htm. Acesso em: 08.04.2011.
} 
Assim como se verificou quando da inclusão do efeito vinculante com a EC $\mathrm{n}^{\circ}$ 03/1993, também o texto da EC n²5/2004 e o da Lei n 11.417/2006 omitiram-se em conferir legitimidade à participação da parte no sistema da edição das súmulas ${ }^{20}$, retirandose do cidadão a oportunidade de defesa direta de direito fundamental no procedimento de proposição, revisão ou cancelamento dos enunciados, em que pese o fato do texto ser resultado dos julgamentos de recursos cujos efeitos são inter partes.

O conceito de súmula vinculante é apresentado como o enunciado, aprovado por no mínimo dois terços dos membros do Supremo Tribunal Federal, que sintetiza reiteradas decisões da Corte sobre uma mesma questão constitucional ${ }^{21}$, não se enquadrando, contudo, como ato de natureza puramente judicial ${ }^{22}$, como ressalta Jorge Amaury Maia Nunes:

[...] a atividade do Supremo Tribunal Federal de que resulta a edição de súmulas vinculantes para os demais órgãos do Poder Judiciário e da Administração Pública não se restringe aos esquemas preconcebidos que reduzem os atos do Estado, como expressão do poder político, a atos legislativos, administrativos ou judiciais. A súmula vinculante não cabe nessa classificação, sendo necessário entendê-la simplesmente como um ato político, fruto do poder político na sua vertente institucional. ${ }^{23}$

Subjaz à instituição da súmula vinculante a pretensão de racionalização da atividade judicial difusa ${ }^{24}$ mediante a solução centralizada de controvérsia envolvendo a validade, a interpretação e a eficácia de normas jurídicas, quando presente o risco de diversificada compreensão judicial da norma, causando insegurança jurídica, e aumento de demanda para o Poder Judiciário, consolidando, a partir do vértice do sistema judicial, representado pelo Supremo Tribunal Federal, a interpretação a ser seguida pelos demais órgãos judiciais.

As semelhanças entre o efeito vinculante do art. 102, $\$ 2^{\circ}$ e o das súmulas do art. 103A da Constituição talvez estejam mais relacionadas ao procedimento para se chegar ao alcance da vinculação do que quanto à extensão dessa vinculação, motivo que autoriza a conclusão de que a pretensão da reforma constitucional foi o de objetivar, tanto quanto

20 Tal omissão foi objeto de críticas em MEDINA, José Miguel Garcia. WAMBIER, Luiz Rodrigues. WAMBIER, Tereza Arruda Alvim. A súmula vinculante vista como meio legítimo para diminuir a sobrecarga de trabalho dos tribunais brasileiros. Revista do Advogado. Ano XXVII, n 92, jul/2007, p. 07/22. São Paulo: AASP, 2007, p. 15-16.

${ }^{21}$ CUNHA, Sérgio Sérvulo da. Aplicação da súmula vinculante. Revista trimestral de direito público. n. 46/ 94, 2004.

22 Mônica Sifuentes entende a súmula vinculante como ato jurisdicional, classificando-a como ato normativo da função jurisdicional que "se situa em uma zona cinzenta da distribuição funcional entre os poderes do Estado, dado o seu caráter de obrigatoriedade e de generalidade, que o aproxima do conteúdo material da lei." In: SIFUENTES, Mônica. Súmula vinculante: um estudo sobre o poder normativo dos tribunais. São Paulo: Saraiva, 2005, p. 275.

${ }^{23}$ NUNES, Jorge Amaury Maia. Segurança jurídica e súmula vinculante. São Paulo: Saraiva, 2010, p. 136.

${ }^{24}$ Tal característica rompe com a tradição européia, criadora do instituto do efeito vinculante, para expandir sua aplicação para "fora do controle abstrato de constitucionalidade". In: LEAL, Roger Stiefelmann. O efeito vinculante na jurisdição constitucional. São Paulo: Saraiva. 2006, p. 144. 
possível o controle difuso de constitucionalidade, reforçando a eficácia subjetiva das decisões da Suprema Corte.

Lembra Paulo Roberto Lyrio Pimenta ${ }^{25}$, entretanto, uma importante distinção no que toca às premissas da vinculação entre as disposições do art. 102 , $₫ 2^{\circ}$ e art. 103-A da Lei fundamental. É que enquanto a vinculação das decisões do controle abstrato aparece como reforço à eficácia subjetiva erga omnes do julgado, a edição da súmula vinculante, nos termos do art. 103-A, transforma a própria natureza concreta dos julgados no controle difuso que passam a apresentar-se como norma jurídica de eficácia geral, independentemente de deliberação do Senado Federal.

A inserção da súmula vinculante revelou uma opção de política judiciária cuja lógica segue a idéia da repercussão geral: fortalecer o entendimento pacificado pela jurisprudência da Suprema Corte, assegurando-lhe autoridade a que devem observância a Administração Pública e todos os órgãos judiciais, à exceção do próprio Supremo Tribunal Federal.

O discurso legitimador da inovação procurou deixar claro que a partir das súmulas seria possível emprestar coerência ao sistema judiciário nacional, pois ela seria o instrumento hábil a substituir a chamada jurisprudência lotérica, consistente nas divergentes interpretações a partir de um mesmo dispositivo normativo, por um parâmetro seguro, definitivo e vinculante, aprovado pela instância judicial mais alta do país.

Tal qual ocorreu à época da edição da EC n 03/1993, o período que antecedeu a promulgação da EC n 45/2004 marcou um debate em torno da adoção das súmulas. De modo geral, as divergências doutrinárias quanto à utilidade e mesmo quanto à constitucionalidade das súmulas vinculantes, agruparam-se de um lado autores ${ }^{26}$ que enxergavam nelas uma alternativa para a crise de insegurança jurídica, excesso de demandas e morosidade, criticados na atuação do Poder Judiciário, e de outro lado ${ }^{27}$ os que viam no

\footnotetext{
${ }^{25}$ PIMENTA, Paulo Roberto Lyrio. Reforma do judiciário. Coord. Fredie Didier Jr., Edvaldo Brito, Saulo José Casali Bahia. São Paulo:a Saraiva, 2006, p. 177.

${ }_{26}$ VELLOSO, Carlos Mário da Silva. Do Poder Judiciário: como torná-lo mais ágil e dinâmico: efeito vinculante e outros temas. Revista de informação legislativa, Brasília, a. 35, n. 138, abr./jun. 1998. p. 7587; CARREIRA ALVIM, José Eduardo. Alternativas para uma maior eficácia da prestação jurisdicional. Revista de processo, São Paulo, Editora Revista dos Tribunais, a. 21, n. 84, out./dez. 1996. p. 185; TOURINHO NETO, Fernando da Costa. Efeito vinculante das decisões do Supremo Tribunal Federal: uma solução para o Judiciário. Revista de informação legislativa, Brasília, a. 32, n. 128, out./dez. 1995. p. 185; RAMOS, Saulo. Efeito vinculante de decisões dos tribunais superiores. Revista brasileira de ciências criminais, São Paulo, Editora Revista dos Tribunais, a. 4, n. 13, jan./mar. 1996. p. 159.

${ }^{27}$ LINS E SILVA, Evandro. Efeito vinculante das súmulas: os assentos da casa da suplicação. ADV Advocacia Dinâmica: boletim informativo semanal, v. 17, n. 35, ago. 1997. p. 448-49; ROCHA, Carmen Lúcia Antunes. Sobre a súmula vinculante. Revista de informação legislativa, Brasília, a. 34, n. 133, jan./mar. 1997. p. 63; DALLARI, Dalmo de Abreu. Judiciário independente e responsável. Revista enfoque jurídico, n.8, ago. 1997. p. 14-15.
} 
instituto a ofensa ao princípio da separação de poderes, afronta à independência judicial e o risco do engessamento da interpretação constitucional.

Sob o ângulo da importância da súmula vinculante para o estudo das transformações da jurisdição constitucional brasileira, duas questões merecem ser levantadas: a função de aproximação entre as vias difusa e concentrada e os efeitos da declaração de inconstitucionalidade in concreto após a edição de enunciado de súmula vinculante.

Como elemento de aproximação, a súmula parece cumprir uma função de "trânsito do modelo difuso-concreto para o concentrado-abstrato" 28 , considerando que não há diferença substancial entre os efeitos produzidos pelas súmulas vinculantes e os das decisões proferidas nas ações de controle abstrato, sujeitando a eventual contrariedade ao entendimento fixado em ambas ao procedimento da reclamação constitucional no Supremo Tribunal Federal.

Se para a deflagração da ação declaratória de constitucionalidade é exigida a demonstração da existência de controvérsia judicial relevante sobre a constitucionalidade de lei ou ato normativo que constitui o objeto da própria ação, a teor do art. 14, III, da Lei $\mathrm{n}^{\circ}$ 9.868/99, a propositura do enunciado de súmula vinculante não pode feita sem a constatação de que o entendimento a ser sumulado já foi reiteradamente decidido pela Suprema Corte, conforme disposição da própria Constituição.

Note-se que, mesmo percorrendo vias distintas, tanto o efeito vinculante das ações de caráter abstrato quanto o das súmulas tem como objetivo a aderência dos demais operadores jurídicos (do Judiciário ou Executivo) ao entendimento fixado pelo Supremo Tribunal Federal, realizando, na prática uma incorporação das decisões do controle difuso no modelo concentrado de controle de constitucionalidade, com base no argumento de preservação da segurança jurídica.

O outro ponto de interesse na análise da súmula vinculante em conexão com o estudo sobre as decisões na jurisdição constitucional brasileira relaciona-se à necessidade de definição sobre quais são as conseqüências da edição da súmula que veicula a declaração de inconstitucionalidade sobre a validade da norma jurídica.

Em regra, a declaração de inconstitucionalidade produzida no controle concreto produz efeitos inter partes e retroativos, enquanto a pronúncia de nulidade através do controle abstrato tem o condão de excluir a norma jurídica do ordenamento, e atinge, além

${ }^{28}$ LEITE, Glauco Salomão. Súmula vinculante e jurisdição constitucional brasileira. Rio de Janeiro: Forense, 2007, p. 70. 
da eficácia, a própria validade da norma, assumindo o Tribunal o papel de legislador negativo.

A tradição brasileira, seguindo o modelo norte-americano sem o acolhimento do stare decisis, desenvolveu-se com foco no tratamento específico dos efeitos das decisões para cada caso concreto julgado, e ainda assim permanece quando o Supremo Tribunal Federal depara-se com o exame de um recurso extraordinário, cabendo exclusivamente ao Senado Federal conferir extensão erga omnes ao acórdão proferido.

Contudo, situação diferente configura-se com a transformação de uma série de julgados no mesmo sentido que, por via de recurso extraordinário, declaram inconstitucional determinada lei ou ato normativo, representando o entendimento consolidado da Corte, e que, portanto, está apto a ser sumulado.

A considerar-se que a edição da súmula vinculante realiza a passagem do controle concreto ao abstrato, a outra conclusão não se pode chegar que não a da revogação da lei ou ato, dada a clara incompatibilidade entre o caráter objetivo, geral e abstrato da súmula em confronto com uma norma jurídica cuja declaração de inconstitucionalidade é objeto do próprio enunciado aprovado pelo Supremo Tribunal Federal.

Essa ampliação da vinculação das decisões no Brasil tem se diferenciado pela expansão de seus efeitos para fora do controle abstrato, sob a pretensão de racionalização da atividade judicial difusa, como parece ser o propósito das súmulas, sem atentar, todavia, para o fato de que a criação do enunciado sumular importa em novo texto, cuja aplicação depende de interpretação direcionada ao caso concreto, que por sua vez possibilita a abertura de novas possibilidades, inclusive a de acesso direto à jurisdição do Supremo Tribunal através do ajuizamento da reclamação constitucional ${ }^{29}$, prevista no art. 102, I, 1, da Constituição Federal.

A questão tem conexão direta com a hipótese de aplicação do art. 52, X, da Constituição de 1988, levantando a perspectiva de que, a partir da EC n 45/2004 e a criação do instituto da súmula vinculante, estaria esvaziada de sentido a manutenção da competência do Senado Federal para suspender a execução de norma declarada inconstitucional de forma incidental pelo Supremo.

\footnotetext{
${ }^{29} \mathrm{O}$ considerável aumento do número de reclamações após o início da vigência da Lei $\mathrm{n}^{\circ}$ 11.417, de 19 de dezembro de 2006, pode ser uma evidência empírica desse diagnóstico. As estatísticas divulgadas pelo STF

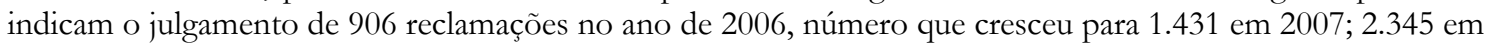
2008; 3.521 em 2009, registrando uma queda para 2.094 em 2010. Dados extraídos do sítio eletrônico: http://www.stf.jus.br/portal/cms/verTexto.asp?servico=estatistica\&pagina=pesquisaClasse Acesso em: 23.09.2011.
} 
Admitir, contudo, que uma função privativa do Senado seja revogada tacitamente com a criação de uma competência do Poder Judiciário não parece, a princípio, adequada com a sistemática constitucional de equilíbrio entre os poderes, consagrada com a doutrina dos freios e contrapesos.

Assim, permanece vigente e plenamente aplicável o inciso $\mathrm{X}$, do art. 52 da Constituição, não se vislumbrando, contudo, utilidade em sua utilização nos casos em que a declaração de inconstitucionalidade reiteradamente afirmada pelo Supremo Tribunal Federal for reduzida à enunciado de súmula vinculante, considerada a eficácia erga omnes que este instrumento confere ao entendimento firmado pelo Tribunal.

\section{Súmula vinculante e stare decisis: uma comparação necessária.}

Apesar de a origem do efeito vinculante ser marcada por uma forte influência da prática judicial desenvolvida com a regra do stare decisis, presente nos países que adotam a tradição jurídica do common law, algumas características podem ser apontadas como evidência de que se tratam de institutos distintos.

No controle de constitucionalidade concentrado está a origem do efeito vinculante, instrumento concebido para evitar a repetição do conteúdo de norma declarada inconstitucional pelo Tribunal Constitucional em decisões judiciais ou administrativas que eventualmente contrariassem o entendimento do órgão responsável pela guarda da Constituição nos países da Europa continental, notadamente os que acolheram a proposta de uma jurisdição constitucional nos moldes propostos por Kelsen.

Por outro lado, a ideia de conferir força vinculante obrigatória ao precedente judicial consistente na regra do stare decisis é fruto da ampla experiência de aplicação do direito de maneira difusa pelos juízes das diversas instâncias do sistema judiciário norte-americano, com o intuito de assegurar relativa estabilidade jurisprudencial, não se constituindo propriamente como prática voltada ao controle de constitucionalidade ${ }^{30}$.

Essa distinção de caráter geral parece conduzir às demais diferenças existentes entre o efeito vinculante as súmulas e o stare decisis. Pois, sendo possível constatar que a rigidez do primeiro deve-se ao fato de sua origem estar na proibição de comportamento contrário à orientação fixada de forma centralizada em um Tribunal, a relativa flexibilidade do segundo (o stare decisis) pode ser atribuída ao fato de que no common law qualquer juízo ou

${ }^{30}$ LEAL, Roger Stiefelmann. O efeito vinculante na jurisdição constitucional. São Paulo: Saraiva. 2006, p. 127. 
tribunal pode deixar de observar o precedente, desde que justificadamente, prática adequada a um modelo de controle judicial difuso.

Sobre esse traço distintivo entre os citados institutos expõe Roger Leal que "enquanto o stare decisis constitui instrumento de coerência interna do Poder Judiciário, o efeito vinculante tem natureza impositiva externa, obrigando, inclusive e principalmente, instâncias não jurisdicionais, notadamente o Poder Legislativo e o Poder Executivo." 31.

Mesmo no caso das súmulas vinculantes em que o enunciado, em tese, é aprovado somente após reiterados julgamentos do Supremo Tribunal Federal e são previstos pela legislação meios para a sua revisão ou o cancelamento, há consideráveis diferenças em comparação à doctrine of stare decisis.

Há de se registrar primeiro uma distinção de competência jurisdicional orgânica. Enquanto nos Estados Unidos não só a Suprema Corte pode firmar um precedente dotado de eficácia obrigatória para todos (binding effects), mas também as demais Cortes federais e 51 estaduais podem fixar orientação abrangente com caráter de stare decisis, no Brasil apenas o Supremo Tribunal Federal pode editar súmulas apoiado na compreensão sobre os fatos dos casos julgados, criando outro texto abstrato sujeito à nova interpretação pelas instâncias ordinárias.

Em segundo lugar, há uma distinção na forma de enxergar os fundamentos do entendimento vinculante obrigatório. Entre os norte-americanos não há a súmula vinculante, mas apenas jurisprudência (o precedente judicial), logo, os operadores do direito têm de se concentrar nos detalhes do caso para entender a norma jurídica como resultado das circunstâncias fáticas do caso paradigma, e, havendo algum fato específico distinto relevante, argumentar em sentido diferente ao da norma, sem desobedecer a força do precedente.

No sistema brasileiro, a prática da utilização da súmula vinculante tem se desenvolvido apenas com a leitura, compreensão e aplicação silogística do texto do enunciado, permanecendo sem observação as particularidades dos fatos que deram origem aos acórdãos, e, consequentemente aos enunciados das súmulas, ensejando a possibilidade de reprodução equivocada de norma idêntica a situações substancialmente díspares.

${ }^{31}$ LEAL, Roger Stiefelmann. O efeito vinculante na jurisdição constitucional. São Paulo: Saraiva. 2006, p. 128. 
Ressalta-se, neste ponto, o problema de se tratar como sinônimas as distintas práticas dos operadores do direito desenvolvidas nas tradições do civil law e do common law ${ }^{32}$.

Há de se registrar provisoriamente, nessa linha de raciocínio, que, embora seja possível constatar na evolução do controle de constitucionalidade brasileiro uma gradual utilização de institutos do common law no processo decisório do Supremo Tribunal Federal (e.g. o stare decisis e o writ of certiorary de um lado, e as súmulas vinculantes e a repercussão geral de outro), como elementos de aproximação entre os modelos concentrado-abstrato e difuso-concreto, ainda prevalece no Brasil, assim como nos países de tradição jurídica do civil law, o uso da lei e não do precedente como ponto de partida para o intérprete, o que limita de certa forma a apreciação comparativa dos fatos ${ }^{33}$ na formação do juízo de valor presente nas decisões judiciais.

\section{Considerações finais.}

Ainda que se considere, como faz Marinoni ${ }^{34}$, como irreversível o processo de objetivação do controle difuso-concreto de constitucionalidade no Supremo Tribunal Federal, a instrumentalização desse processo não pode, ou pelo menos não deveria, ser feita com a singela incorporação do instituto da ratio decidendi no common law para dar eficácia à aplicação dos precedentes vinculantes, sem antes compreender a complexa dimensão de

\footnotetext{
32 Nesse preciso ponto, esclarece Edil Batista Junior que: “A tradição civilista tem por fundamento o direito legislado. Os sistemas jurídicos a ela vinculados tendem a se estruturar sobre um discurso axiomático: uma normatização preventiva, que visa, em face da generalidade que determina, ao enquadramento de um grande campo de ações ainda não ocorridas. A tradição do common Law, por outro lado, está ligada ao pensamento problemático, estruturado no caso concreto. Repudia, em tese o raciocínio apriorístico legal e toma como modelo para a decisão presente aquela, adotada em caso ocorrido que lhe seja análogo. Vê-se assim, que as duas estruturas jurídicas reproduzem, à sua maneira, dois postulados gnoseológicos que se opõem há séculos: racionalismo e empirismo." In: BATISTA JUNIOR, Edil. O Supremo Tribunal Federal e o monopólio da hermenêutica constitucional no Brasil: a interpretação como ato de poder. Curitiba: Juruá, 2011, p. 73.

33 Observação semelhante é feita por Patrícia Perrone Campos Mello: "as decisões judiciais proferidas nos países do 'civil law' partem de uma moldura previamente delineada pela lei, o que não necessariamente ocorre no 'common law'. Tal moldura auxilia, por si só, uma seleção preliminar dos fatos relevantes. (...) Essa pré-valoração dos fatos, que é efetuada pelo próprio legislador, seleciona os eventos a serem tidos em conta em certos contextos, excluindo outros, podendo por isso, atenuar o detalhamento fático necessário para se alcançar uma decisão. No caso do Brasil, existem também alguns aspectos processuais limitadores da discussão sobre a matéria de fato, em especial em sede de controle de constitucionalidade." In: MELLO, Patrícia Perrone Campos. Precedentes: o desenvolvimento judicial do direito no constitucionalismo contemporâneo. Rio de Janeiro: Renovar, 2008, p. 144. No mesmo sentido: MARINONI, Luiz Guilherme. Elaboração dos conceitos de ratio decidendi (fundamentos determinantes da decisão) e obiter dictum no direito brasileiro. In: MARINONI, Luiz Gulherme et al. A força dos precedentes: estudos dos cursos de mestrado e doutorado em direito processual civil da UFPR. Salvador: JusPodivm. 2010, p. 251-252.

34 MARINONI, Luiz Guilherme. Elaboração dos conceitos de ratio decidendi (fundamentos determinantes da decisão) e obiter dictum no direito brasileiro. In: MARINONI, Luiz Guilherme et al. A força dos precedentes: estudos dos cursos de mestrado e doutorado em direito processual civil da UFPR. Salvador: JusPodivm, 2010, p. 252.
} 
apreciação fática dos casos, tarefa que o Supremo Tribunal Federal não parece $\mathrm{e}^{35}$ disposto a assumir.

Sob a ótica da construção dos fundamentos da decisão de inconstitucionalidade, vislumbra-se outra dificuldade. Como a competência do Supremo Tribunal Federal para o julgamento das ações diretas é sempre originária, a teor do art. 102, I, a, da Constituição, em regra ${ }^{36}$, os fatos e fundamentos apresentados pelas partes são postos à apreciação judicial pela primeira vez já na mais alta instância do Poder Judiciário, excluindo dos debates as variadas possibilidades de construção dos próprios fundamentos de decidir da Corte, decorrentes do contraditório instalado entre as partes e das decisões proferidas nas instâncias judiciais ordinárias, elementos presentes no controle difuso-concreto de constitucionalidade.

Cabe registrar, nesse particular, que, além das dificuldades de identificação de uma autêntica ratio decidendi dos julgados do Supremo, a formatação de diferentes técnicas de decisão experimentadas no common law, cuja essência esteja na minuciosa apreciação comparativa de precedentes, não parece se ajustar como método de trabalho de uma Corte que, embora tenha diminuído significativamente o seu número de processos ${ }^{37}$, ainda trabalha com um quantitativo muito superior a um patamar razoável.

Assim, do ponto de vista institucional, mesmo contabilizando-se as alterações legislativas no sentido de reduzir a carga de trabalho do STF, e os esforços da própria Corte em liberar-se da função de instância recursal ${ }^{38}$ para atuar exclusivamente como Tribunal Constitucional, é fato que o Supremo ainda mantém competências de órgão do Poder Judiciário.

A transformação da Suprema Corte brasileira em um Tribunal Constitucional, e a consequente mudança dos instrumentos de decisão utilizados por um órgão que venha a ter por missão exclusiva a defesa da Constituição, nos moldes propostos por Kelsen ${ }^{39}$,

\footnotetext{
35 A própria jurisdição constitucional difusa desenvolvida em sede de recurso extraordinário não admite a competência da Corte para o reexame de fatos e provas. Cf. Súmula $n^{\circ} 279$ do STF.

36 A instauração da ADC, conforme disciplina do art. 14, III, a Lei no 9.868/99, está condicionada à demonstração de controvérsia judicial relevante sobre o tema.

${ }^{37}$ Desde a implementação da repercussão geral é possível notar uma queda no número de processos no STF, porém, o número permanece alarmante, em 2010, por exemplo, o Supremo Tribunal Federal proferiu 103.869 julgamentos, conforme estatística divulgada no sítio eletrônico do Tribunal. Disponível em: http://www.stf.jus.br/portal/cms/verTexto.asp?servico=estatistica\&pagina=movimentoProcessual. Acesso em: 7 jun. 2011.

38 Pesquisa divulgada recentemente pela Fundação Getulio Vargas mostra que aproximadamente $92 \%$ dos processos em trâmite no Supremo Tribunal Federal referem-se a recursos, e que apenas 3\% do total de processos na Corte tratam especificamente de matéria constitucional. Relatório com detalhes sobre o movimento processual do Tribunal disponível em: http://www.supremoemnumeros.com.br/wpcontent/uploads/2011/05/I-Relatório-Supremo-em-Números.pdf Acesso em: 26 mai. 2011.

${ }^{39}$ KELSEN, Hans. Jurisdição constitucional. São Paulo: Martins Fontes, 2003, p. 263.
} 
precisa ser objeto de reflexão envolvendo o amplo debate entre todos os destinatários das decisões.

Uma discussão sobre a conversão do Supremo em um Tribunal Constitucional, contudo, deve abranger não só as "vantagens" frequentemente divulgadas como a redução de demanda; a concentração do controle de constitucionalidade e ampliação do efeito vinculante das decisões na jurisdição constitucional, mas também o “ônus” democrático de garantir uma revitalização do pensamento da Corte com o estabelecimento de mandatos periódicos ${ }^{40}$ para os ministros, cuja escolha privilegie uma composição plural e a efetiva participação da sociedade na nomeação; e especialmente cuide das garantias de acesso da coletividade à formação das razões de decidir do Tribunal.

Deixar de lado essa discussão e acreditar que a experiência jurisprudencial autorreferente do Supremo Tribunal Federal consubstanciada na "canonização" dos fundamentos de suas decisões oferece respostas suficientemente adequadas com base na "força normativa" da Constituição pode representar, por sua vez, um crescimento da dificuldade dos demais poderes e da própria sociedade em debater o conteúdo das decisões da Corte, contribuindo para a consolidação da ideia de que o Tribunal é o verdadeiro "intérprete autêntico" do texto constitucional.

Se pela via inversa, o regime democrático implica o estabelecimento de uma correspondência entre governantes e governados, pressupondo que o cidadão pode ser identificado, a um só tempo, como destinatário e autor das normas jurídicas, a vinculação da interpretação constitucional não pode legitimar-se apenas em razão das palavras proferidas por um Tribunal, por mais importante que seja a posição ocupada por ele na organização das instituições, pois a Constituição não pertence a ninguém, ela é o fruto de uma construção aberta de toda a comunidade.

\footnotetext{
40 Nesse sentido é a Proposta de Emenda à Constituição nº 342/09, do Dep. Flávio Dino, que fixa o mandato em 11 anos, vedada a recondução, e muda a forma de escolha dos ministros, retirando a chefia do Poder Executivo a exclusividade da nomeação, incluindo a indicação de 2 membros pelo Senado Federal; 2 pela Câmara dos Deputados; 2 pelo próprio STF, e 5 pelo Presidente da República. Todas as escolhas, de acordo com o projeto, recairiam sobre nomes constantes de listas tríplices com participação de outros tribunais (STJ e TST), conselhos (CNJ, CNMP, OAB), além de órgãos colegiados das faculdades de direito com programa de doutorado em funcionamento há pelo menos 10 anos. Inteiro teor da proposta disponível em: http://www.camara.gov.br/sileg/integras/641368.pdf Acesso em: 13 jun. 2011.
} 


\section{Referências bibliográficas}

BATISTA JUNIOR, Edil. O Supremo Tribunal Federal e o monopólio da hermenêutica constitucional no Brasil: a interpretação como ato de poder. Curitiba: Juruá, 2011.

CARREIRA ALVIM, José Eduardo. Alternativas para uma maior eficácia da prestação jurisdicional. Revista de processo, São Paulo, Editora Revista dos Tribunais, a. 21, n. 84, out./dez. 1996.

CUNHA, Sérgio Sérvulo da. Aplicação da súmula vinculante. Revista trimestral de direito público. n. 46/94, 2004.

DALLARI, Dalmo de Abreu. Judiciário independente e responsável. Revista enfoque jurídico, n.8, ago. 1997.

DANTAS, Ivo. Constituição e processo. $2^{a}$ edição. Curitiba: Juruá, 2007.

DUXBURY, Neil. The nature and authority of precedent. New York: Cambridge University Press. 2008.

GALINDO, Bruno. A teoria da constituição no common law. Reflexões teóricas sobre o peculiar constitucionalismo britânico. Revista de informação legislativa. Senado Federal, Brasília a. 41 n. 164, p. 303-316, out./dez. 2004.

HÄBERLE, Peter. Hermenêutica constitucional. A sociedade aberta dos intérpretes da constituição: contribuição para a interpretação pluralista e procedimental da constituição. Trad. Gilmar Ferreira Mendes. Porto Alegre: Fabris, 1997.

KELSEN, Hans. Jurisdição constitucional. São Paulo: Martins Fontes, 2003.

LEAL, Roger Stiefelmann. O efeito vinculante na jurisdição constitucional. São Paulo: Saraiva. 2006.

LEITE, Glauco Salomão. Súmula vinculante e jurisdição constitucional brasileira. Rio de Janeiro: Forense, 2007.

LINS E SILVA, Evandro. Efeito vinculante das súmulas: os assentos da casa da suplicação. ADV Advocacia Dinâmica: boletim informativo semanal, v. 17, n. 35, ago. 1997.

MARINONI, Luiz Guilherme. Elaboração dos conceitos de ratio decidendi (fundamentos determinantes da decisão) e obiter dictum no direito brasileiro. In: A força dos precedentes: estudos dos cursos de mestrado e doutorado em direito processual civil da UFPR. Salvador: Jus Podivm. 2010.

MEDINA, José Miguel Garcia. WAMBIER, Luiz Rodrigues. WAMBIER, Tereza Arruda Alvim. A súmula vinculante vista como meio legítimo para diminuir a sobrecarga de trabalho dos tribunais brasileiros. Revista do Advogado. Ano XXVII, n 92, jul/2007, p. 07/22. São Paulo: AASP, 2007.

MELlO, Patrícia Perrone Campos. Precedentes: o desenvolvimento judicial do direito no constitucionalismo contemporâneo. Rio de Janeiro: Renovar, 2008. 
NUNES, Jorge Amaury Maia. Segurança jurídica e súmula vinculante. São Paulo: Saraiva, 2010.

PIMENTA, Paulo Roberto Lyrio. Reforma do judiciário. Coord. Fredie Didier Jr., Edvaldo Brito, Saulo José Casali Bahia. São Paulo:a Saraiva, 2006.

PORTO, Sérgio Gilberto. Sobre a common law, civil law e o precedente judicial. Estudo em homenagem ao Professor Egas Moniz de Aragão. Academia Brasileira de Direito Processual Civil. Disponível em: http://www.abdpc.org.br/abdpc/artigos/Sergio\%20Portoformatado.pdf . Acesso em: 13 de julho de 2010.

RAMOS, Saulo. Efeito vinculante de decisões dos tribunais superiores. Revista brasileira de ciências criminais, São Paulo, Editora Revista dos Tribunais, a. 4, n. 13, jan./mar. 1996.

ROCHA, Carmen Lúcia Antunes. Sobre a súmula vinculante. Revista de informação legislativa, Brasília, a. 34, n. 133, jan./mar. 1997.

SALAVERRIA, Juan Igartua. La fuerza vinculante del precedente judicial. Isegoría, $\mathrm{n}^{\circ} 35$, julio-diciembre, 2006.

SARTORI, Giovanni. A teoria da democracia revisitada: o debate contemporâneo, Vol. I. tradução: Dinah de Abreu Azevedo. São Paulo: Ática, 1994.

SIFUENTES, Mônica. Súmula vinculante: um estudo sobre o poder normativo dos tribunais. São Paulo: Saraiva, 2005.

SILTALA, Raimo. A theory of precedent: from analytical positivism to a post-analytical philosophy of law. Portland: Hart Publishing, 2000.

SODERO, Eduardo. Sobre el cambio de los precedentes. Revista Isonomía, Instituto Tecnológico Autónomo de Mexico, nº 21. Octubre/2004.

SOUZA, Marcelo Alves Dias de. Do precedente judicial à súmula vinculante. Curitiba: Juruá, 2006.

TOURINHO NETO, Fernando da Costa. Efeito vinculante das decisões do Supremo Tribunal Federal: uma solução para o Judiciário. Revista de informação legislativa, Brasília, a. 32, n. 128, out./dez. 1995.

VELLOSO, Carlos Mário da Silva. Do Poder Judiciário: como torná-lo mais ágil e dinâmico: efeito vinculante e outros temas. Revista de informação legislativa, Brasília, a. 35, n. 138, abr./jun. 1998. 